\title{
Partially Healed Malaligned Distal Radius Fracture. Surgical Treatment in Patients older than 70 Years
}

\section{Fractura de radio distal parcialmente consolidada en malposición. Tratamiento quirúrgico en pacientes mayores de 70 años}

\author{
Marcos Cruz-Sánchez ${ }^{1,2}$ Jaime De la Torre-Rojo ${ }^{20}$ \\ 1 Orthopedic Surgery and Traumatology Service, Hospital Dos De \\ Maig - Consorci Sanitari Integral, Barcelona, Spain \\ 2 Traumaunit, Centro Médico Teknon, Barcelona, Spain \\ Rev Iberam Cir Mano 2020;48:20-26.
}

Cristóbal Martínez-Andrade ${ }^{2}$

\begin{abstract}
Address for correspondence Marcos Cruz Sánchez, PhD, Servicio de Cirugía Ortopédica y Traumatología, Hospital Dos De Maig - Consorci Sanitari Integral, Barcelona, España

(e-mail: marcoscruzsanchez85@gmail.com).
\end{abstract}

\begin{abstract}
Keywords

- distal radius fracture

- malunion

- reconstructive surgery
\end{abstract}

\section{Resumen}

Introduction Management of distal radius fractures remains controversial despite their high frequency. Elderly patients specifically present a high rate of secondary displacement, sometimes requiring a complex reconstructive surgery. The surgical treatment of displaced fractures evolving for several weeks in elderly patients has not been clearly reflected in the literature. This study aims to show clinical and radiological outcomes from this particular situation.

Material and Methods Retrospective study of 31 cases of distal radius fractures with more than 2 weeks of evolution. Fractures were graded according to the Fernández's classification. Pre- and postoperative radiological studies were carried out to evaluate the degree of correction achieved. A clinical evaluation was performed using the Mayo Wrist Score. Data on arthroscopy and bone substitutes use, specific surgical tips and complications were also collected.

Results Thirty-one patients with a mean age of 76 years old were operated for distal radius fracture with a delay in surgical treatment of 22 days. The most frequent fracture pattern was Fernández type III (38.7\%). The clinical outcome according to the Mayo Wrist Score was 81.94 points with no relationship to fracture pattern or arthroscopic assistance. A statistically significant improvement was achieved for the correction of radial inclination, joint gap and ulnar variance. No statistically significant improvement was achieved in volar tilt correction. Complications were observed in $12.9 \%$ of the cases.

Conclusions Delayed surgical treatment of distal radius fracture in elderly patients provides similar results to those observed in other age groups and time of evolution. Despite not being the ideal scenario for the surgeon, it should be considered to avoid functional deterioration in this fragile age group.

Introducción El manejo de las fracturas de radio distal sigue en controversia pese a su elevada frecuencia. Concretamente en los pacientes de edad avanzada se observa una tasa de desplazamiento secundario elevada y que en ocasiones requiere de una cirugía received

March 3, 2020

accepted

March 13, 2020
DOI https://doi.org/

10.1055/s-0040-1712091. ISSN 1698-8396.
Copyright $\odot 2020$ Thieme Revinter

Publicações Ltda, Rio de Janeiro, Brazil
License terms

c) $(1) \$$ 
reconstructiva más compleja. El escenario de tratamiento quirúrgico de la fractura desplazada y con varias semanas de evolución en pacientes de edad avanzada no se ha reflejado con claridad en la literatura. El objetivo del estudio es mostrar los resultados clínicos y radiológicos de esta situación tan particular como frecuente.

Material y Método Estudio retrospectivo de 31 casos de fracturas de radio distal con más de 2 semanas de evolución. Se clasificaron según la clasificación de Fernández y se realizó un estudio radiológico pre y postoperatorio dónde se valoró el grado de corrección conseguido. Se realizó una valoración clínica mediante el Mayo Wrist Score y se describieron las complicaciones. El uso de la artroscopia, la utilización de sustitivos óseos y la realización de gestos quirúrgicos específicos también fueron recogidos.

Resultados 31 pacientes con una media de edad de 76 años fueron intervenidos de fractura de radio distal con una demora en el tratamiento quirúrgico de 22 días. El patrón de fractura más frecuente fue el tipo III de Fernández (38.7\%). El resultado clínico según el Mayo Wrist Score fue de 81.94 puntos, no encontrando relación con el patrón de fractura ni con la asistencia artroscópica. Se consiguió una mejoría

Palabras clave

- fractura de radio distal

- mala consolidación

- cirugía reconstructiva estadísticamente significativa para la corrección de la inclinación radial, gap articular y varianza cubital. No se consiguió una mejoría estadísticamente significativa para el tilt dorsal. Se observaron complicaciones en el $12.9 \%$.

Conclusiones El tratamiento quirúrgico de la fractura de radio distal diferida en el paciente de edad avanzada ofrece unos resultados similares a otros grupos de edad y tiempo de evolución. Pese a no ser el escenario ideal para el cirujano, se debe tener en cuenta para evitar el deterioro funcional en este frágil grupo de edad.

\section{Introduction}

Distal radius fracture (DRF) was, is and will be one of the most frequent injuries in all life stages and reason for consultation in any health center. In recent years, specifically in Spain, the aging index has registered its historical maximum, over $120 \%$ (120 people over 64 years old for every 100 people under 16 years old). In fact, within this elderly population, the rate of over-aging has increased due to lifestyle and healthcare improvements. ${ }^{1}$ These facts led to an increase in DRF cases and modified its management.

Currently, DRF in elderly patients has several peculiar aspects. Firstly, the low bone quality associated with a high comminution degree results in fracture instability, implying in a gradual closed reduction loss and complicating the decision-making process (- Figure $\mathbf{1}$ ). Secondly, regarding orthopedic treatment, the concept that, despite a suboptimal radiological outcome, the functional result will be favorable remains valid. ${ }^{2}$ Thirdly, when the patient finally is evaluated by a hand surgery specialist (often more than 2 weeks after trauma), the literature supporting surgical treatment in "partially misaligned fractures" is scarce.

The purpose of this study was to evaluate radiological and functional outcomes of delayed surgical treatment in elderly patients with DRF. The hypothesis was that fracture anatomical and stable reconstruction offers satisfactory results, similar to those observed in other age groups.

\section{Material and Methods}

\section{Study Population}

All patients referred to the Hand Surgery Unit for surgical treatment of DRF from September 2015 to June 2018 were reviewed. Inclusion criteria were patients older than 70 years old with a DRF with three to six weeks of evolution. Exclusion criteria were patients outside the previously established age and evolution range, active infection, sequelae of previous fracture or complete fracture consolidation. A group of 31 patients ( 27 women and 4 men) with a mean age of 76 years old (range, 70-91) constituted the study population. There were no losses at follow-up.

\section{Clinical Design}

This was a retrospective study with initial patient assessment and follow-up by two hand surgery experts. A preoperative evaluation was carried out to collect sociodemographic data and determine relevant medical history, comorbidities and autonomy degree. Radiographs were serially evaluated, including images from the initial fracture and those obtained after reduction (performed at the emergency room), postoperatively and at the end of follow-up period. Fractures were classified according to Fernández. ${ }^{3}$ Radial inclination, volar tilt, ulnar variance, and joint gap were measured before and after surgery. Radiological analysis consisted in comparison with normal values described in the literature. ${ }^{4}$ Functional outcomes were evaluated according to the Mayo Wrist Score ${ }^{5}$ at the end of the follow-up period. At the surgical technique level, the performance of arthroscopy, the use of a bone graft and the 


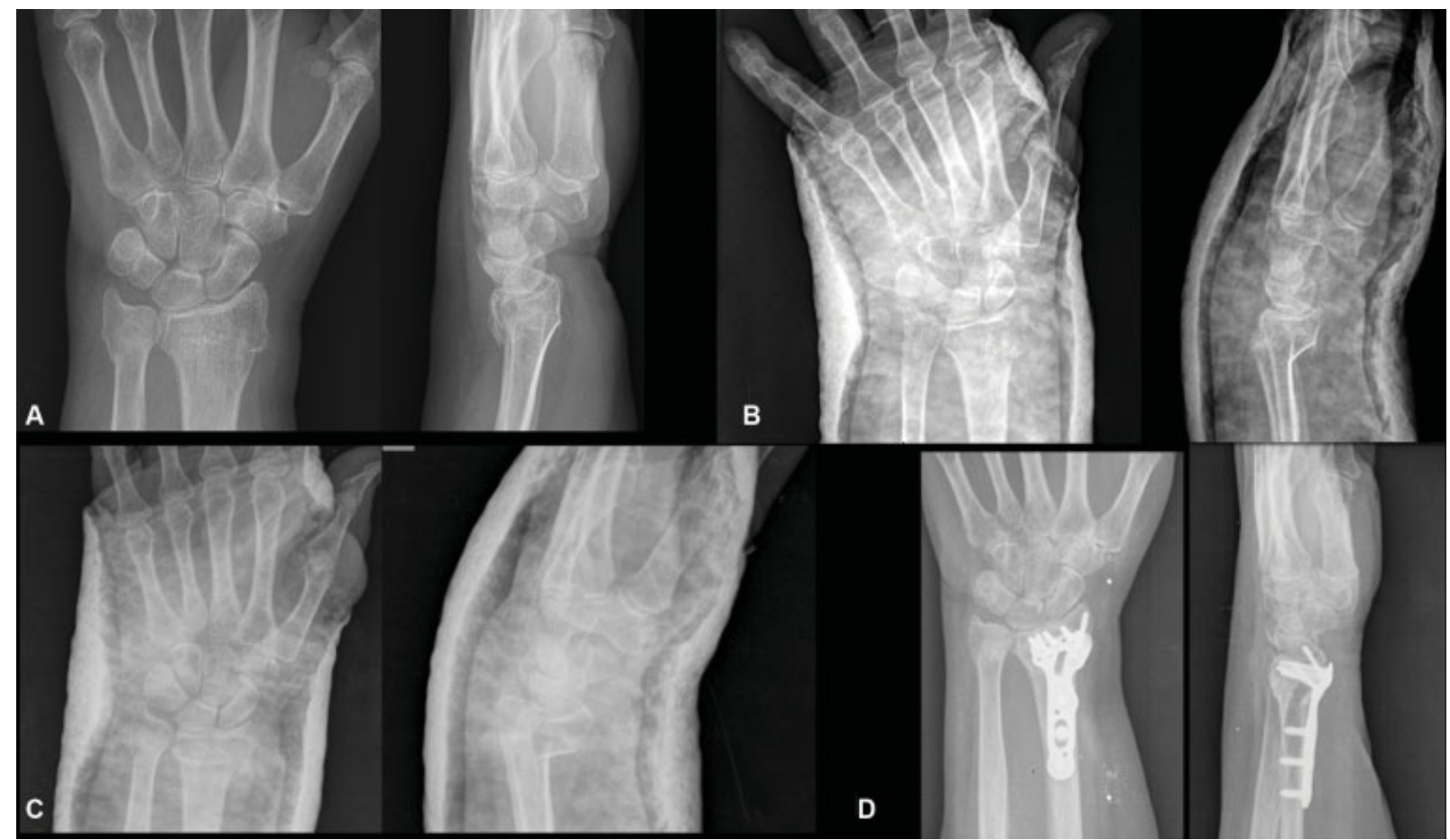

Fig. 1 Example of radial fracture and unstable distal ulna. (A) Initial fracture. (B) Closed reduction. (C). Radiological parameters worsening after 3 weeks. (D) Definitive treatment.

treatment of associated ulnar fractures were analyzed. Lastly, postoperative complications were assessed.

\section{Indication and Surgical Technique}

All patients were evaluated preoperatively by orthopedic surgeons specialized in hand pathology. Surgical treatment indication was based on a detailed study of comorbidities in patients with adequate physical and cognitive status. The following radiological criteria were applied for surgical treatment indication: dorsal angulation higher than $20^{\circ}$, radiocarpal subluxation, joint gap higher than $2 \mathrm{~mm}$ and ulnar variance higher than $2 \mathrm{~mm}$ secondary to radial fracture focus shortening. ${ }^{6}$ All therapeutic possibilities, with their respective advantages and disadvantages, were explained to the patient, allowing him to choose the definitive treatment option. All patients signed an informed consent form for joint fracture reconstructive surgery and wrist arthroscopy.

Under axillary block and using a proximal ischemia cuff in the arm, an osteosynthesis with volar plate was performed following the guidelines described by Orbay. ${ }^{7}$ Since surgical treatment was delayed, the fibro-osseous tissue at the fracture (volar and dorsal) focus had to be removed using a bone curette and gouge forceps. Particularities of surgical treatment regarding an acute fracture included the extended approach with complete diaphyseal pronation for fibrotic tissue debridement and dorsal fragments reduction, the use of a Hintermann distractor at fracture focus to restore the radio-ulnar relationship at the frontal plane, the use of an anatomical plate to restore fracture angulation and the use of arthroscopy as a tool to remove the interposed tissue at the articular level and check the reduction ( - Figure 2 ). The ulnar edge of radius reconstruction was used as a reference for fracture reduction ${ }^{8}$ and volar angulation was restored using an anatomical plate with cortical screws. Reduction and initial fixation were checked routinely with fluoroscopy; arthroscopy using $3 / 4$ and $6 \mathrm{R}$ portals, $5 \mathrm{~kg}$ of zenith traction, elbow flexed at $90^{\circ}$ and forearm in neutral position was performed in cases with persistence of some type of joint gap after reduction maneuvers remained or doubts regarding the presence of intra-articular osteosynthesis material. Arthroscopic evaluation was not performed in cases with a satisfactory reduction intraoperatively and good stability provided by the osteosynthesis material. Lastly, fixation was completed with angular stability screws, definitive arthroscopic verification and closure by planes.

\section{Postoperative Period}

After the procedure, a plaster dorsal splint was used for two weeks, followed by rehabilitation therapy and comfort orthoses until approximately the sixth week depending on fracture type. Per protocol clinical-radiological controls were performed at 2 weeks, 6 weeks, 3 months, 6 months and 12 months. At the end of the follow-up period, the Mayo Wrist Score was evaluated, and revisit guidelines were delivered.

\section{Statistical Analysis}

Data was analyzed using the SPSS statistical package (SPSS Inc, Chicago) version 25.0. For quantitative variables, mean and standard deviation (SD) values were used; for qualitative variables, numbers and percentages were used. Radiological data and postoperative functional outcomes were analyzed using the Chi-square test considering a 95\% level of statistical significance $(p<0.05)$. 


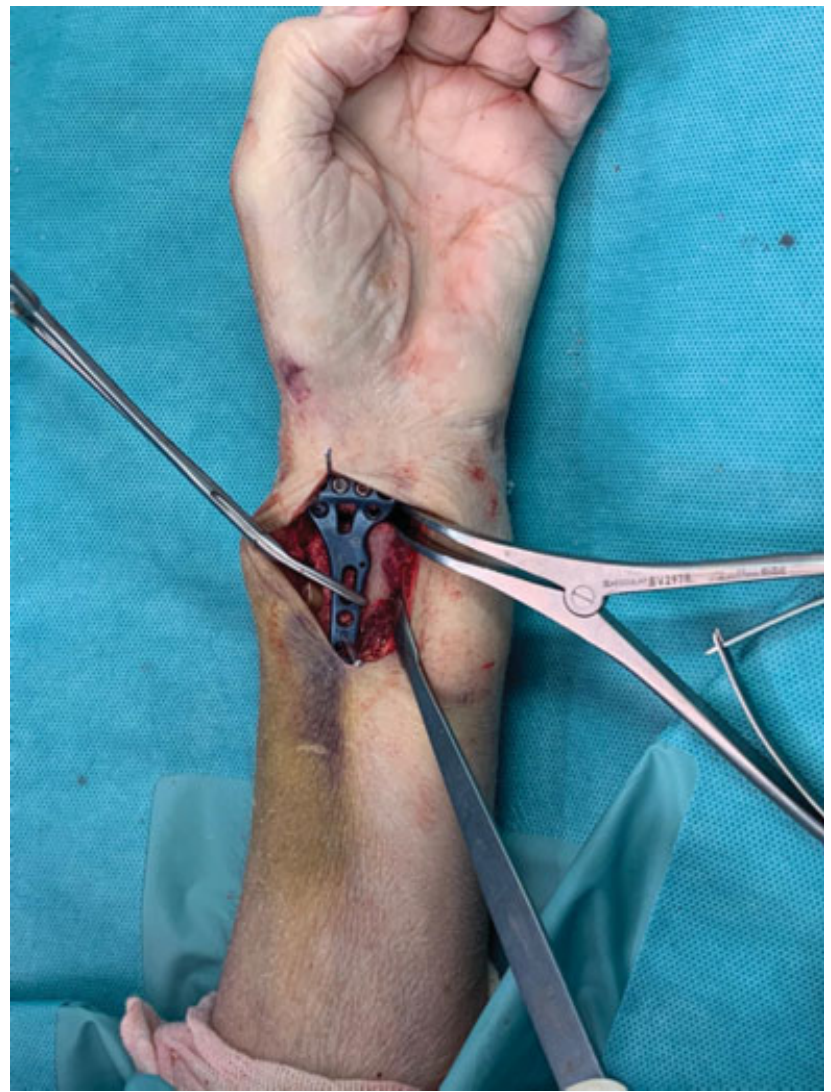

Fig. 2 Distractor application at fracture site to restore the radio-ulnar relationship in fractures with severe shortening.

\section{Results}

In total, 31 patients ( 27 females and 4 males) underwent volar plate osteosynthesis; fracture consolidation was achieved in all of them. Mean age was 76 years old (range, 70-91). Median delay time until intervention was 22 days (range, 15-49). Mean postoperative follow-up time was 17 months (SD, 9.6). Fourteen cases $(45.2 \%)$ presented ulnar fractures, mostly with styloid avulsion, in which osteosynthesis was not performed, except for three cases requiring plate stabilization due to metaphyseal-diaphyseal involvement. According to the Fernández classification, 11 cases (35.5\%) were classified as type I, 4 cases as type II (12.9\%), 12 cases as type III (38.7\%) and 4 cases as type IV (12.9\%); there was no type V cases. Initial reduction was satisfactory in 17 cases (54.8\%). At the preoperative radiological study, a radial inclination of $16.87^{\circ}$ (SD, 5.9), a cubital variance of $3.54 \mathrm{~mm}$ (SD, 2.99), a dorsal angulation of $15.8^{\circ}$ (SD, 14.7) and a joint gap of $1.74 \mathrm{~mm}(\mathrm{SD}, 2.3 \mathrm{~mm}$ ) were observed. The postoperative radiological study showed a statistically significant correction of joint gap, radial inclination and ulnar variance, with the following measurements: radial inclination of $23.99^{\circ}(\mathrm{SD}, 4.5)$ ( $p$ 0.05), ulnar variance of $0.97 \mathrm{~mm}(\mathrm{SD}, 1.5)$ (p 0.00), joint gap of $0.1 \mathrm{~mm}(\mathrm{SD}, 0.3)(p 0.01)$. No statistically significant improvement in angle correction was been obtained, with a mean volar tilt of $1.74^{\circ \circ}(\mathrm{SD}, 6.02)(p$ 0.053). During surgery, arthroscopic assistance was used in 17 cases (54.8\%), and a bone graft was employed as a structural support due to a metaphyseal defect in four cases (12.9\%).
Functional outcomes included an average score of 81.94 (SD, 10.46), classified as "good" according to the Mayo Wrist Score system. No statistically significant correlation with the fracture pattern or arthroscopic assistance was observed. There were no intraoperative complications, but postoperative complications were observed in four cases (12.9\%): a joint protrusion of the screw, two cases of distal screw loosening and one case of flexor pollicis longus tendon rupture 2 years after the intervention. Nine cases (29\%) presented pseudoarthrosis of the ulnar styloid base; however, since the patients were clinically asymptomatic and did not require salvage surgical treatment, these were not counted as complications (-Table $\mathbf{1}$ ).

\section{Discussion}

Firstly, this study describes the functional and radiological outcomes of the delayed surgical treatment of DRF in a specific population. Secondly, some particularities considered to achieve anatomical reconstruction and fixed fragment stability are described at a technical level. Thirdly, results analysis suggests a relationship between anatomical reconstruction and satisfactory functional outcome; however, the hypothesis cannot be confirmed due to sample size and the retrospective design of the study.

There is abundant medical literature on DRF management. Due to its high frequency, different professionals can participate in its treatment, including emergency physicians, traumatologists, hand surgeons, rehabilitators and physical therapists. In addition, this is an injury with a high degree of displacement and re-displacement, specifically 30\% during the first 10 days and $29 \%$ more 10 to 20 days after the fracture. ${ }^{9}$ Despite its frequency, there is strikingly little literature on surgical treatment in cases partial misaligned consolidation in elderly patients with good functional and cognitive features. As such, this type of patient needs to be identified and assessed both in a multidisciplinary and specialized way.

The main controversy in the management of this type of injury is that, currently, on the one hand, there is literature supporting orthopedic treatment despite a non-anatomical reduction and/or clinical deformity, ${ }^{10,11}$ especially in elderly patients. On the other hand, there is also literature ${ }^{12}$ indicating that DRF malunion results in loss of function in the upper limb, even 2 years after fracture and considering surgical treatment benefits ${ }^{11}$ This difference of opinion is probably due to several aspects, including lack of specificity of assessment instruments, samples heterogeneity and study designs. In this age group, loss of upper limb function has a greater impact on quality of life, since most daily activities require using the hands. ${ }^{13}$ Therefore, efforts must be focused on narrowing the surgical indication. First of all, regarding quality of life, a patient who lives alone and performs all daily activities with no help from others (for example, going to the doctor's office) must be considered an active individual. Second, regarding the need for reconstructive surgery, the goal is to achieve a reduction as close as possible to normal anatomy. The main parameters are volar angulation, radial 


\begin{tabular}{|c|c|c|c|c|c|c|c|c|c|c|c|c|c|c|c|c|c|c|c|c|c|c|c|c|c|c|c|c|c|c|c|}
\hline 总 & 2 & - & $\frac{0}{2}$ & $\frac{0}{2}$ & 2 & - & 2) & 2 & 2 & $\frac{0}{2}$ & $\frac{0}{2}$ & 2 & 2 & - & 2) & 2 & 2 & $\frac{0}{2}$ & 2 & $\frac{0}{z}$ & $\frac{0}{2}$ & $\frac{0}{z}$ & $\frac{0}{2}$ & 2 & $\frac{0}{z}$ & 2 & $\stackrel{0}{z}$ & $\frac{0}{2}$ & $\stackrel{0}{z}$ & 2) & $\stackrel{0}{2}$ \\
\hline 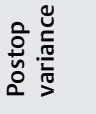 & 0 & 0 & 0 & 0 & $\sim$ & 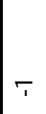 & 0 & 0 & $\sim$ & $m$ & $\sim$ & 0 & 0 & 7 & $\sim$ & 0 & 0 & 0 & in & 0 & 0 & $m$ & $\sim$ & 0 & in & 0 & $\sim$ & $m$ & 0 & 0 & - \\
\hline 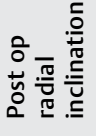 & $\stackrel{\tilde{N}}{\sim}$ & $\bar{v}$ & $\stackrel{6}{\circ}$ & શิ & $\stackrel{\sim}{\sim}$ & $\stackrel{\infty}{\sim}$ & $\stackrel{i}{ }$ & $\stackrel{\Perp}{\sim}$ & $\lesssim$ & $\stackrel{\llcorner}{\sim}$ & $\ddot{\sim}$ & $\stackrel{d}{\sim}$ & $\stackrel{i}{ }$ & શ & $\stackrel{\stackrel{2}{\sim}}{\sim}$ & ㅎ & $\ddot{\sim}$ & $\stackrel{\llcorner}{\sim}$ & ని & $\lesssim$ & $\stackrel{\searrow}{\sim}$ & $\stackrel{\llcorner}{\sim}$ & $\stackrel{\llcorner}{\sim}$ & $\stackrel{\llcorner}{\sim}$ & $\simeq$ & $\stackrel{\Perp}{\longleftarrow}$ & $\bar{\sim}$ & $\stackrel{\bullet}{\leftarrow}$ & $\stackrel{\Xi}{\sim}$ & $\stackrel{\infty}{\sim}$ & 10 \\
\hline 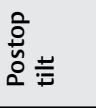 & $m$ & † & 0 & 음 & 0 & เn & $\stackrel{\varphi}{\varphi}$ & 9 & $\wedge$ & - & $\sigma$ & 0 & $\frac{0}{1}$ & 0 & 0 & $m$ & 0 & $N$ & $\sim$ & T & $m$ & $\stackrel{\circ}{-}$ & $\simeq$ & $\circ$ & in & 0 & 0 & $\sigma$ & $\sim$ & 0 & $\infty$ \\
\hline 高䓂 高 & $m$ & 6 & 0 & $\sigma$ & 0 & $\wedge$ & 0 & $\nabla$ & 0 & - & $\sim$ & - & 0 & $N$ & - & - & $m$ & 0 & 0 & $\sim$ & $\nabla$ & 0 & 0 & 0 & 0 & 0 & 0 & 0 & $m$ & in & 0 \\
\hline 竞 & $N$ & 0 & 0 & 0 & 0 & $\infty$ & - & in & $\infty$ & 0 & $\nabla$ & in & $\sim$ & $\sim$ & 6 & 0 & 0 & $m$ & $\infty$ & 0 & 0 & 0 & $m$ & $\sim$ & 0 & $\nabla$ & + & $\mp$ & 0 & in & $m$ \\
\hline
\end{tabular}

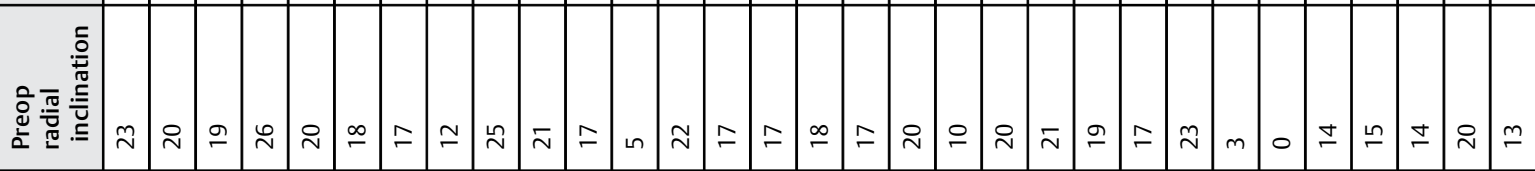

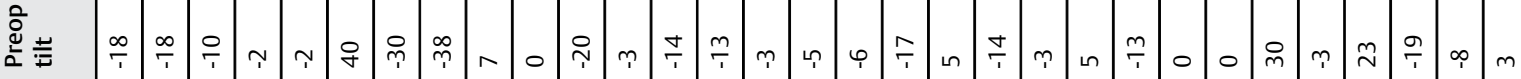


height, and radiocarpal and radioulnar joint relationships restoration, with acceptable displacement limits of $20^{\circ}$ for dorsal deformity, less than $3 \mathrm{~mm}$ for joint step and $<3 \mathrm{~mm}$ for ulnar plus; in addition, unstable patterns that may result in joint subdislocation must be avoided ${ }^{14}$ (dorsal or volar Barton fracture).

Obviously, from the surgical point of view, the best time to treat a fracture is within the first days after its occurrence. It has been described that, as early as 2 weeks, a fibrous callus formation makes treatment difficult. ${ }^{7}$ Therefore, to avoid the development of a reflex sympathetic dystrophy, surgical treatment must be indicated as soon as an intolerable displacement is detected to obtain a faster recovery. Even so, the medical literature describes that there were no differences in DASH scores from patients younger than 55 years old who underwent surgery for DRF either at approximately 8 or 30 days after trauma. ${ }^{15} \mathrm{~A}$ fracture with several weeks of evolution must be treated through a soft tissue approach and release for correct reduction. Although it is not the purpose of this study, arthroscopy was deemed useful to remove the fibrotic tissue located in the fracture focus at the radiocarpal joint facet level, with fragments manipulation with a Freer-type dissector and synoviotome ${ }^{16}$ (-Figure 3); this allows for a fine articular reduction and checks osteosynthesis stability. In contrast to acute management, the use of bone grafts in cases of large metaphyseal defects must be considered, as required in four cases from our series. The literature describes the use of bone substitutes with satisfactory clinical-radiological results. ${ }^{17}$

Regarding the functional outcome of DRF surgical treatment, the literature indicates that fixed angle locked volar plates have good results in elderly patients regardless of the assessment instrument, ${ }^{18}$ with $85 \%$ of good outcomes and a $8 \%$ rate of complications one year after surgery. Jupiter ${ }^{6}$ described excellent outcomes in 18 from 20 patients older than 60 years old treated for DRF, with $15 \%$ of complications. In our series, functional outcomes were similar, with $12.9 \%$ of complications, consisted with data published so far, even with younger populations and shorter evolution times. Therefore, these data invite reconstructive surgery to be considered despite the fact that it is not the best scenario for the surgeon; a satisfactory outcome is expected with no increase in complication rates. There are other fixation methods, including Kischner wires and/or external fixators, ${ }^{19,20}$ reportedly with favorable outcomes, but with an irregular complication rate, ranging from $15 \%$ to $45 \%$.

We conclude that the delayed surgical treatment of DRF in elderly patients offers similar results to those observed in other age groups and different times of evolution. The appropriate surgical indication for these patients is really important; despite not being the ideal setting for the surgeon, it must be considered to avoid functional deterioration in this fragile age group.

Limitations of this study included its retrospective design and the absence of a control group, not allowing the determination of which is the best treatment for a condition that, unfortunately, will be increasingly frequent. Therefore, considering outcomes from surgical treatment, it would be

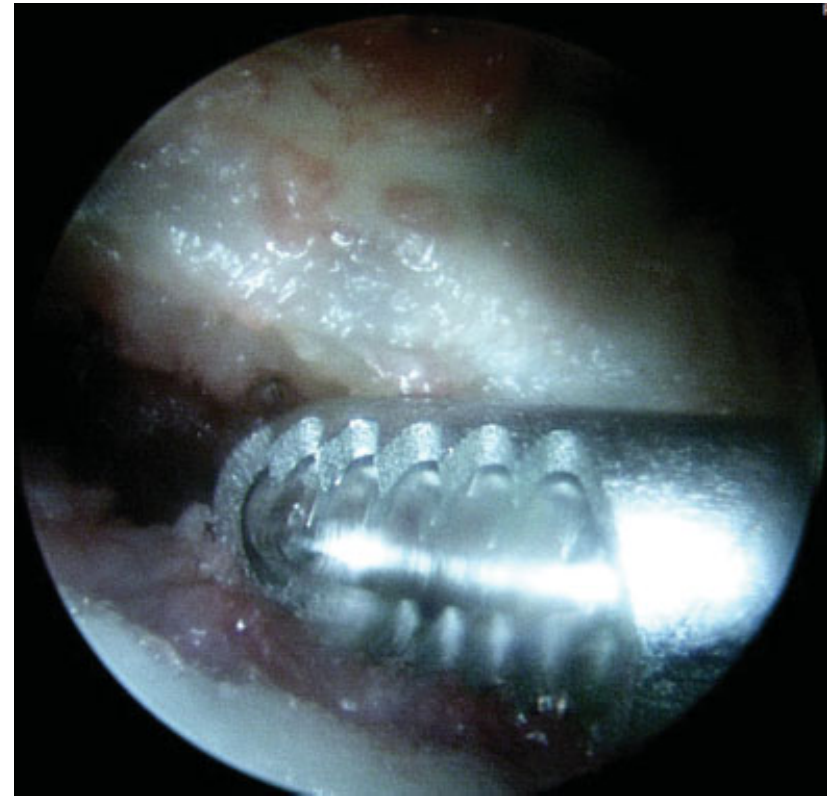

Fig. 3 Images of arthroscopic treatment (fibrotic tissue debridement) using a synoviotome.

appropriate to propose studies with a higher level of evidence, even of a multicentric nature, to clarify the optimal management of elderly patients with unstable distal radial fractures.

\section{Conflict of Interest}

The authors have no conflict of interests to declare.

\section{References}

1 Instituto Nacional de Estadística (España). https://www.ine.es/welcome.shtml (Consulta: Diciembre 2019

2 Arora R, Gabl M, Gschwentner M, Deml C, Krappinger D, Lutz M. A comparative study of clinical and radiologic outcomes of unstable colles type distal radius fractures in patients older than 70 years: nonoperative treatment versus volar locking plating. J Orthop Trauma 2009;23(04):237-242

3 Fernandez DL. Distal radius fracture: the rationale of a classification. Chir Main 2001;20(06):411-425

4 Mann FA, Wilson AJ, Gilula LA. Radiographic evaluation of the wrist: what does the hand surgeon want to know? Radiology 1992;184(01):15-24

5 Amadio PC, Berquist TH, Smith DK, Ilstrup DM, Cooney WP III, Linscheid RL. Scaphoid malunion. J Hand Surg Am 1989;14(04): 679-687

6 Jupiter JB, Ring D, Weitzel PP. Surgical treatment of redisplaced fractures of the distal radius in patients older than 60 years. J Hand Surg Am 2002;27(04):714-723

7 Wijffels MME, Orbay JL, Indriago I, Ring D. The extended flexor carpi radialis approach for partially healed malaligned fractures of the distal radius. Injury 2012;43(07):1204-1208

8 Rapley JH, Kearny JP, Schrayer A, Viegas SF. Ulnar translation, a commonly overlooked, unrecognized deformity of distal radius fractures: techniques to correct the malalignment. Tech Hand Up Extrem Surg 2008;12(03):166-169

9 Porter M, Stockley I. Fractures of the distal radius. Intermediate and end results in relation to radiologic parameters. Clin Orthop Relat Res 1987;(220):241-252

10 McQueen M, Caspers J. Colles fracture: does the anatomical result affect the final function? J Bone Joint Surg Br 1988;70(04):649-651 
11 Young BT, Rayan GM. Outcome following nonoperative treatment of displaced distal radius fractures in low-demand patients older than 60 years. J Hand Surg Am 2000;25(01):19-28

12 Brogren E, Wagner P, Petranek M, Atroshi I. Distal radius malunion increases risk of persistent disability 2 years after fracture: A prospective cohort study hand. Clin Orthop Relat Res •••38 (03):526-531

13 Gehrmann SV, Windolf J, Kaufmann RA. Distal radius fracture management in elderly patients: a literature review. J Hand Surg Am 2008;33(03):421-429

14 Thompson GH, Grant TT. Barton's fractures-reverse Barton's fractures. Confusing eponyms. Clin Orthop Relat Res 1977; (122):210-221

15 Weil YA, Mosheiff R, Firman S, Liebergall M, Khoury A. Outcome of delayed primary internal fixation of distal radius fractures: a comparative study. Injury 2014;45(06):960-964
16 Del Piñal F, Clune J. Arthroscopic Management of Intra-articular Malunion in Fractures of the Distal Radius. Hand Clin 2017;33 (04):669-675

17 Huber FX, Hillmeier J, Herzog L, McArthur N, Kock HJ, Meeder PJ. Open reduction and palmar plate-osteosynthesis in combination with a nanocrystalline hydroxyapatite spacer in the treatment of comminuted fractures of the distal radius. J Hand Surg [Br] 2006; 31(03):298-303

18 Schupp A, Tuttlies C, Möhlig T, Siebert HR. [Distal radius fractures. $2.4 \mathrm{~mm}$ locking compression plates. Are they worth the effort?] Chirurg 2003;74(11):1009-1017

19 Pritchett JW. External fixation or closed medullary pinning for unstable Colles fractures? J Bone Joint Surg Br 1995;77(02):267-269

20 Cannegieter DM, Juttmann JW. Cancellous grafting and external fixation for unstable Colles' fractures. J Bone Joint Surg Br 1997;79 (03):428-432 